\title{
HIV Screening Among U.S. Physicians, 1999-2000
}

\author{
Kyle T Bernstein, Ph.D., Sc.M., ${ }^{1,2}$ Elizabeth Begier, M.D., M.P.H. ${ }^{1}$ Ryan Burke, M.P.H., ${ }^{1,3}$ \\ Adam Karpati, M.D., M.P.H., ${ }^{1}$ and Matthew Hogben, Ph.D. ${ }^{4}$
}

\begin{abstract}
In 2006, the Centers for Disease Control and Prevention (CDC) put forth recommendations for routine HIV screening for all individuals aged 13-64. The frequency and correlates of HIV screening among U.S. physicians in 2000 were examined to provide baseline data for evaluating the implementation of the 2006 CDC HIV testing guidelines through a survey mailed to a random sample of U.S. physicians in the American Medical Association's Masterfile. The primary outcome was self-reported HIV screening of asymptomatic male and nonpregnant female patients. A total of 4133 (adjusted completion rate of $70.2 \%$ ) returned a completed survey. Overall, 1133 (28.4\%) of physicians reported HIV screening. U.S. physicians, who were female, black, Hispanic, practiced in a city of more than 250,000 people, diagnosed HIV in the past 2 years, or followed up with patients to see if they notified their sexual partners, were more likely to screen their patients for HIV. Emergency medicine, internal medicine, and pediatrics specialists were less likely to screen than family/general practitioners. In 2000, only a quarter of U.S. physicians reported screening their patients for HIV and these rates varied by physician characteristics and practice settings.
\end{abstract}

\section{Introduction}

A FTER NEARLY 25 years have passed since the beginning of the HIV / AIDS epidemic, 2004 yielded an increase of new diagnoses nationally. ${ }^{1}$ A coordinated public health response to HIV/AIDS hinges on widespread availability of HIV antibody testing. Traditionally, HIV testing has been approached from a risk-based perspective, where antibody testing is focused among populations considered at increased risk (i.e., men who have sex with men, injection drug users, those diagnosed with a sexually transmitted infection). In late 2006, the Centers for Disease Control and Prevention (CDC) revised its recommendations for HIV testing, urging HIV screening for all patients aged 13-64 years in areas where the prevalence is greater than $0.1 \%$ or as yet undetermined. ${ }^{2}$ Others have also advocated a move away from risk-based HIV testing toward routine screening. ${ }^{3-5}$ However, some data have suggested that risk-based testing is a more cost-effective approach to HIV case detection than universal testing. ${ }^{6}$ As a testament to the value of such structurallevel changes with regard to increasing HIV testing, prenatal screening has been successful in reducing perinatal HIV infection and is considered one of public health's triumphs. ${ }^{7}$

A 2004 estimate suggested that nearly $40 \%$ of HIV infec- tions were diagnosed within one year of AIDS. ${ }^{1}$ For the infected individual, late HIV diagnosis may lead to a worse long-term prognosis given the delay in initiating antiretroviral therapy and treatment for opportunistic infections. ${ }^{8-10}$ From the public health perspective, early diagnosis allows individuals to know their HIV serostatus, often resulting in a reduction or elimination of risk behaviors. ${ }^{11}$

Several local surveys have been published assessing HIV testing practices among prenatal care providers. ${ }^{12-16}$ These surveys suggest that prenatal HIV screening has improved over time, and is quite high $(>90 \%)$ in several areas. ${ }^{12-16} \mathrm{~A}$ study of family practice clinicians in Rhode Island and Mississippi found that over $93 \%$ of providers would recommend an HIV test to a high-risk patient, yet less than $50 \%$ recommend HIV testing to sexually active patients aged $18-50 .{ }^{17}$

Additionally, in Rhode Island and Mississippi, only 14\% and $2 \%$ of the surveyed providers reported offering an HIV test to more than $50 \%$ of their patient populations, respectively. ${ }^{17}$ We are aware of no previously published national surveys of HIV testing practices.

As efforts are made to introduce HIV screening as a standard component of medical encounters, both institutional and provider concordance with screening recommendations will be vital. Here, we examine factors associated with of-

${ }^{1}$ New York City Department of Health and Mental Hygiene, Bureau of HIV/AIDS Prevention and Control, New York, New York.

${ }^{2}$ NYU School of Medicine, Department of Emergency Medicine, New York, New York.

${ }^{3}$ CDC /CSTE Applied Epidemiology Fellowship Program, Atlanta, Georgia.

${ }^{4}$ Centers for Disease Control and Prevention, Atlanta, Georgia. 
fering HIV screening to males and nonpregnant females among a 1999-2000 survey of American physicians. Although the survey predates the new CDC testing guidelines by 6 years, it is the most recent extant large-scale survey of screening and testing practices among physicians. Therefore, these data serve as our best baseline for assessing the pre2006 attitudes and practices of physicians with respect to widespread HIV testing. Understanding what distinguishes a physician who offers HIV screening from one who does not can guide future efforts to implement routine HIV testing.

\section{Materials and Methods}

This survey of U.S. physicians has been described elsewhere. ${ }^{18}$ In short, 7300 physicians were randomly selected from the American Medical Association Masterfile and mailed a survey. A cash incentive was included along with a postage-paid return envelope. Up to three reminder notices were sent to nonrespondents. The overall adjusted response rate was $70.2 \% .{ }^{18}$ The sample included U.S. physicians who: (1) specialized in obstetrics/gynecology (OB/GYN), internal medicine, general or family practice, emergency medicine, or pediatrics; (2) spent at least half of their professional time in direct patient care; and (3) cared for patients between the ages of 13 and 60 years. The demographic characteristics of the responding physicians did not differ from the characteristics of practicing physicians in the United States. ${ }^{19}$

The intention of the survey was to assess provider knowledge and practice regarding diagnosis, reporting and partner notification for sexually transmitted diseases (STDs) and HIV. ${ }^{18}$ This analysis focuses exclusively on HIV screening (i.e., testing asymptomatic patients for HIV). Along with capturing demographic data and information about the physicians' practice, the survey evaluated attitudes regarding the utility of STD and HIV reporting and partner notification.

Specifically, physicians were asked "Which asymptomatic patients do you screen for [HIV]?" and answered yes or no for each of males, nonpregnant females, and pregnant females. If physicians reported screening either males or nonpregnant females, they were considered to offer routine HIV screening, although they may not have screened all their patients in each category. The 138 respondents who did not respond to the HIV screening questions were excluded from this analysis.

Characteristics of physicians who did and did not offer HIV screening were compared using $t$ tests for continuous data and chi-square statistics for categorical data. Univariate associations between physician characteristics and the offering of HIV screening were assessed with odds ratios (ORs) and their accompanying 95\% confidence limits were estimated through logistic regression models including only the covariate and the outcome (HIV screening). Multivariate logistic regression models were created to examine independent characteristics associated with HIV screening. Logistic regression models were compared and the final model determined through likelihood ratio testing.

\section{Results}

A total of 3995 physicians returned completed surveys and responded to either question regarding testing asympto- matic males or non-pregnant females for HIV (Table 1). The mean age of the physicians returning the survey was 46.1 years. Over $70 \%$ of the participating physicians were male, and nearly three quarters were white. Approximately a quarter practiced in a large city (greater than 250,000 inhabitants). The largest proportion of respondents were family or general practitioners, followed by internists, and pediatricians (response rates by specialty were similar). About equal proportions were self-employed and employed in an office. Respondents reported practicing for a mean of 17.7 years. Over a third reported never diagnosing an HIV case before.

Among respondents, $1133(28.4 \%)$ reported screening either asymptomatic males and/or nonpregnant females. Univariate ORs for offering HIV screening to male and nonpregnant female patients are also shown in Table 1. Female and Black, Hispanic, or Asian physicians were more likely to offer HIV screening. Physicians practicing in the Midwest and Southern regions of the United States were less likely to offer their patients HIV screening than the West Coast. Additionally, compared to family and general practice, physicians practicing emergency medicine, and pediatrics were less likely to offer HIV screening. Providers working in large cities were $43 \%$ more likely to offer screening. Those who were employees in an office or clinic, compared to being selfemployed or a partner in an office or clinic, were $28 \%$ more likely to provide asymptomatic HIV testing. However, U.S. physicians working in private settings, versus public settings, were significantly less likely to offer HIV screening. Compared to providers who never had diagnosed HIV, those who had diagnosed a patient with HIV in the past 5 years were more likely to offer testing to their patients.

Several attitudinal characteristics were associated with the offering of HIV screening (Table 1). U.S. physicians who reported usually or always collecting sexual partner information $(\mathrm{OR}=1.42,95 \%$ confidence interval [CI]:1.13-1.78), check that HIV cases' partners have been notified (OR = $1.78,95 \%$ CI:1.52-2.08), refer partner names to the health department $(\mathrm{OR}=1.30,95 \% \mathrm{CI}$ : 1.09-1.56), and report patient names to the health department $(\mathrm{OR}=1.37$, 95\% CI:1.17-1.61) were more likely to offer HIV screening. While doctors who believed that HIV and AIDS were reportable to the health department were no more likely to offer HIV screening than those who were unsure, those who did not believe HIV (OR $=0.56,95 \%$ CI: $0.43-0.73$ ) or AIDS (OR = $0.61,95 \%$ CI: $0.44-0.84)$ was reportable were less likely to offer screening. Furthermore, physicians who did not believe that encouraging patients to contact their partners or that reporting sexual contacts to the health department was worthwhile were less likely to offer HIV screening.

Multivariate logistic regression models identified several independent factors associated with HIV screening (Table 1). Females, black, and Hispanic physicians and those practicing in large cities were more likely to offer their patients HIV screening. Practicing in the southern United States, in a private clinic, or specializing in emergency medicine, internal medicine, and pediatrics (compared to family/general practice) were shown to be inversely related to likelihood of HIV screening. Only two attitudinal factors remained significant in the final adjusted model: usually or always checking that patient's partners were notified (adjusted odds ratio $[A O R]=1.41,95 \%$ CI: $1.19-1.68)$ and the belief that there is benefit to encouraging AIDS patients to contact sexual part- 
Table 1. Characteristics of a Sample of U.S. Physicians and Univariate with Multivariate Odds Ratios for Screening of Asymptomatic Male or Nonpregnant Female Patients for HiV

\begin{tabular}{|c|c|c|c|c|c|}
\hline Characteristic & $\mathrm{n}$ & $\%$ Sample & $\%$ HIV screening & $\begin{array}{l}\text { Univariate } \\
\text { OR }(95 \% \mathrm{CI})\end{array}$ & $\begin{array}{c}\text { Adjusted } \\
\text { OR }(95 \% C I)^{\mathrm{a}}\end{array}$ \\
\hline Total & 3995 & & 28.4 & & \\
\hline Age (mean/median) & 46.1 & $45^{\mathrm{b}}$ & & $1.00(0.99-1.00)$ & \\
\hline Years Practicing (mean/median) & 17.7 & $10.5^{\mathrm{b}}$ & & $1.00(0.99-1.00)$ & \\
\hline Male & 2796 & 70.0 & 25.3 & 1.0 & 1.0 \\
\hline Female & 1150 & 29.1 & 35.9 & 1.65 (1.43-1.92) & $1.66(1.39-2.00)$ \\
\hline West & 866 & 21.9 & 32.3 & 1.0 & 1.0 \\
\hline Midwest & 996 & 25.2 & 27.0 & $0.77(0.63-0.95)$ & $0.86(0.67-1.10)$ \\
\hline South & 1257 & 31.8 & 26.0 & $0.74(0.61-0.89)$ & $0.63(0.50-0.80)$ \\
\hline East & 837 & 21.2 & 29.9 & $0.89(0.73-1.10)$ & $0.89(0.69-1.14)$ \\
\hline White & 2958 & 74.0 & 25.8 & 1.0 & 1.0 \\
\hline Black & 160 & 4.0 & 48.1 & $2.67(1.91-3.73)$ & $2.17(1.44-3.21)$ \\
\hline Hispanic & 196 & 4.9 & 38.3 & 1.79 (1.31-2.43) & 1.51 (1.04-2.17) \\
\hline Asian & 500 & 12.5 & 33.0 & 1.42 (1.15-1.75) & 1.09 (0.84-1.41) \\
\hline Other & 181 & 4.5 & 29.8 & $1.23(0.86-1.72)$ & $1.01(0.63-1.61)$ \\
\hline Family/general practice & 1396 & 34.9 & 33.9 & 1.0 & 1.0 \\
\hline Emergency medicine & 379 & 9.5 & 7.9 & $0.17(0.11-0.25)$ & $0.18(0.12-0.28)$ \\
\hline Internal medicine & 840 & 21.0 & 30.7 & $0.87(0.72-1.04)$ & $0.68(0.55-0.86)$ \\
\hline OB/GYN & 635 & 15.9 & 35.0 & $1.05(0.86-1.28)$ & $1.01(0.79-1.30)$ \\
\hline Pediatrics & 745 & 18.7 & 20.1 & $0.49(0.40-0.61)$ & $0.44(0.34-0.50)$ \\
\hline$<250 \mathrm{~K}$ & 3037 & 76.0 & 26.6 & 1.0 & \\
\hline City $\geq 250 \mathrm{k}$ & 958 & 24.0 & 34.0 & $1.43(1.22-1.67)$ & 1.37 (1.13-1.67) \\
\hline $\begin{array}{l}\text { Self employed or partner in } \\
\text { practice of clinic }\end{array}$ & 1841 & 48.1 & 26.5 & 1.0 & \\
\hline Employed in office or clinic & 1726 & 45.1 & 31.5 & $1.28(1.11-1.48)$ & \\
\hline Indept contractor/other & 261 & 6.8 & 20.3 & $0.71(0.52-0.98)$ & \\
\hline Solo practice & 922 & 23.7 & 29.8 & 1.0 & \\
\hline Single specialty & 1758 & 45.2 & 24.2 & $0.75(0.63-0.90)$ & \\
\hline Multi-specialty & 766 & 19.7 & 32.9 & $1.15(0.94-1.42)$ & \\
\hline Managed care & 260 & 6.7 & 40.0 & 1.57 (1.18-2.09) & \\
\hline Other & 188 & 4.8 & 33.0 & $1.16(0.83-1.62)$ & \\
\hline Public clinic & 505 & 12.8 & 35.8 & 1.0 & 1.0 \\
\hline Private clinic & 3446 & 87.2 & 27.3 & $0.67(0.55-0.82)$ & $0.63(0.49-0.80)$ \\
\hline \multicolumn{6}{|l|}{ Last time diagnosed HIV } \\
\hline Never & 1511 & 38.1 & 22.6 & 1.0 & 1.0 \\
\hline Within 2 years & 1066 & 26.8 & 37.7 & $2.07(1.74-2.46)$ & $1.73(1.38-2.16)$ \\
\hline $2-5$ years & 841 & 21.2 & 29.7 & $1.45(1.20-1.75)$ & $1.19(0.94-1.51)$ \\
\hline $5-10$ years & 438 & 11.0 & 22.8 & $1.01(0.79-1.30)$ & $0.82(0.61-1.11)$ \\
\hline More than 10 years ago & 115 & 2.9 & 26.1 & $1.21(0.78-1.86)$ & $1.21(0.70-2.09)$ \\
\hline $\begin{array}{l}\text { Usually or always collect } \\
\text { partner information }\end{array}$ & 372 & 11.9 & 35.8 & $1.42(1.13-1.78)$ & \\
\hline $\begin{array}{l}\text { Usually or always follow-up } \\
\text { to see if partners notified }\end{array}$ & 1530 & 49.1 & 35.0 & $1.78(1.52-2.08)$ & $1.41(1.19-1.68)$ \\
\hline $\begin{array}{c}\text { Usually or always send partner } \\
\text { names to health department }\end{array}$ & 725 & 23.3 & 33.5 & $1.30(1.09-1.56)$ & \\
\hline $\begin{array}{l}\text { Usually or always send patient } \\
\text { name to health department }\end{array}$ & 1833 & 59.7 & 31.9 & $1.37(1.17-1.61)$ & \\
\hline Unsure if HIV is provider reportable & 1129 & 30.3 & 22.2 & 1.0 & \\
\hline Believes HIV is provider reportable & 2239 & 60.1 & 31.8 & $0.91(0.72-1.16)$ & \\
\hline Believes HIV is not provider reportable & 358 & 9.6 & 33.8 & $0.56(0.43-0.73)$ & \\
\hline
\end{tabular}


Table 1. Characteristics of a Sample of U.S. Physicians and Univariate with Multivariate Odds Ratios for Screening of Asymptomatic Male or Nonpregnant Female Patients for HIV (Cont.)

\begin{tabular}{|c|c|c|c|c|c|}
\hline Characteristic & $\mathrm{n}$ & $\%$ Sample & $\%$ HIV screening & $\begin{array}{l}\text { Univariate } \\
\text { OR }(95 \% C I)\end{array}$ & $\begin{array}{c}\text { Adjusted } \\
\text { OR }(95 \% C I)^{\mathrm{a}}\end{array}$ \\
\hline $\begin{array}{l}\text { Believes AIDS is not provider } \\
\text { reportable }\end{array}$ & 1100 & 29.5 & 22.6 & 1.0 & \\
\hline Believes AIDS is provider reportable & 2339 & 62.8 & 32.0 & $0.77(0.56-1.06)$ & \\
\hline Unsure if AIDS is provider reportable & 286 & 7.7 & 29.7 & $061(0.44-0.84)$ & \\
\hline $\begin{array}{l}\text { HIV reporting is not at all or slightly } \\
\text { worthwhile }\end{array}$ & 294 & 7.7 & 25.5 & $0.83(0.63-1.09)$ & \\
\hline $\begin{array}{l}\text { AIDS reporting is not at all or } \\
\text { slightly worthwhile }\end{array}$ & 299 & 7.8 & 25.1 & $0.81(0.62-1.07)$ & \\
\hline $\begin{array}{l}\text { HIV reporting of names is not at all } \\
\text { or slightly worthwhile }\end{array}$ & 525 & 13.8 & 27.2 & $0.92(0.75-1.13)$ & \\
\hline $\begin{array}{l}\text { AIDS reporting of names is not at all } \\
\text { or slightly worthwhile }\end{array}$ & 531 & 13.9 & 27.1 & $0.91(0.74-1.12)$ & \\
\hline $\begin{array}{l}\text { Encouraging HIV patients to contact } \\
\text { partners is not at all or slightly } \\
\text { worthwhile }\end{array}$ & 207 & 5.4 & 21.3 & $0.65(0.46-0.92)$ & \\
\hline $\begin{array}{l}\text { Encouraging AIDS patients to contact } \\
\text { partner is not at all or slightly } \\
\text { worthwhile }\end{array}$ & 214 & 53.6 & 20.1 & $0.61(0.43-0.85)$ & $0.66(0.44-0.99)$ \\
\hline $\begin{array}{l}\text { Reporting HIV patients contacts is } \\
\text { not at all or slightly worthwhile }\end{array}$ & 939 & 25.1 & 25.9 & $0.82(0.69-0.97)$ & \\
\hline $\begin{array}{l}\text { Reporting AIDS patients contacts is } \\
\text { not at all or slightly worthwhile }\end{array}$ & 944 & 25.3 & 25.8 & $0.82(0.69-0.97)$ & \\
\hline $\begin{array}{l}\text { Believes colleagues never contact } \\
\text { HIV partners }\end{array}$ & 1258 & 36.1 & 27.4 & $0.89(0.76-1.04)$ & \\
\hline $\begin{array}{l}\text { Believes colleagues never contact } \\
\text { AIDS partners }\end{array}$ & 1255 & 36.1 & 27.5 & $0.90(0.77-1.04)$ & \\
\hline
\end{tabular}

aAdjusted for all other covariates listed.

${ }^{b}$ Represents median value.

ners $(\mathrm{AOR}=0.66,95 \% \mathrm{CI}: 0.44-0.99)$ were both associated with HIV screening.

The distribution of HIV screening of male and nonpregnant female patients was examined separately by the gender and specialty of the responding providers (Table 2). Physician gender did not moderate screening rates among emergency medicine and OB/GYN practitioners, but female physicians in the remaining three practice areas (pediatrics, internal medicine, and family/general practice) were significantly more likely to offer HIV screening to both their male and nonpregnant female patients.

\section{Discussion}

HIV screening has been shown to be cost effective in all but extremely low prevalence populations (well below 1\% HIV seroprevalence). ${ }^{4,6,20}$ In this sample of U.S. physicians, only $28 \%$ reported offering HIV screening to their asymptomatic male or non-pregnant female patients. Female, African American, and Hispanic physicians, and those working in large cities, were more likely to provide screening than others. Emergency medicine and pediatrics providers were significantly less likely to offer HIV screening. Diagnosing an $\mathrm{HIV}$ infection within the past 2 years was associated with
HIV screening, as was following-up with patients to confirm sexual partners were notified.

The data presented in this paper were collected in 2000 and represent a cross-sectional portrait of physician attitudes and behaviors at that point in time. These data, however, represent the most recent national-level estimates available. Some data reflect screening on the basis of likely higher prevalence (i.e., physicians in larger cities were more likely to screen than other physicians). Moreover, no guidance existed then to promote universal screening, so the finding that not all providers screen asymptomatic patients for HIV is neither a surprise nor an indicator of substandard practice.

Nonetheless, some findings reflect to some extent a failure of pre-2000 recommendations to influence testing likelihood. For example, in 1993 the CDC recommended routine screening of patients for HIV in hospital settings where the prevalence of HIV was $1 \%$ or greater. ${ }^{21}$ Many clinical sites in urban centers in the United States reported HIV prevalences in excess of the $1 \%$ threshold, yet routine screening was not implemented. Updated counseling and testing guidance released in $2001^{22}$ and the Advancing HIV Prevention (AHP) Initiative in $2003^{23}$ may have resulted in increased screening rates not reflected in this survey. Guidance and 


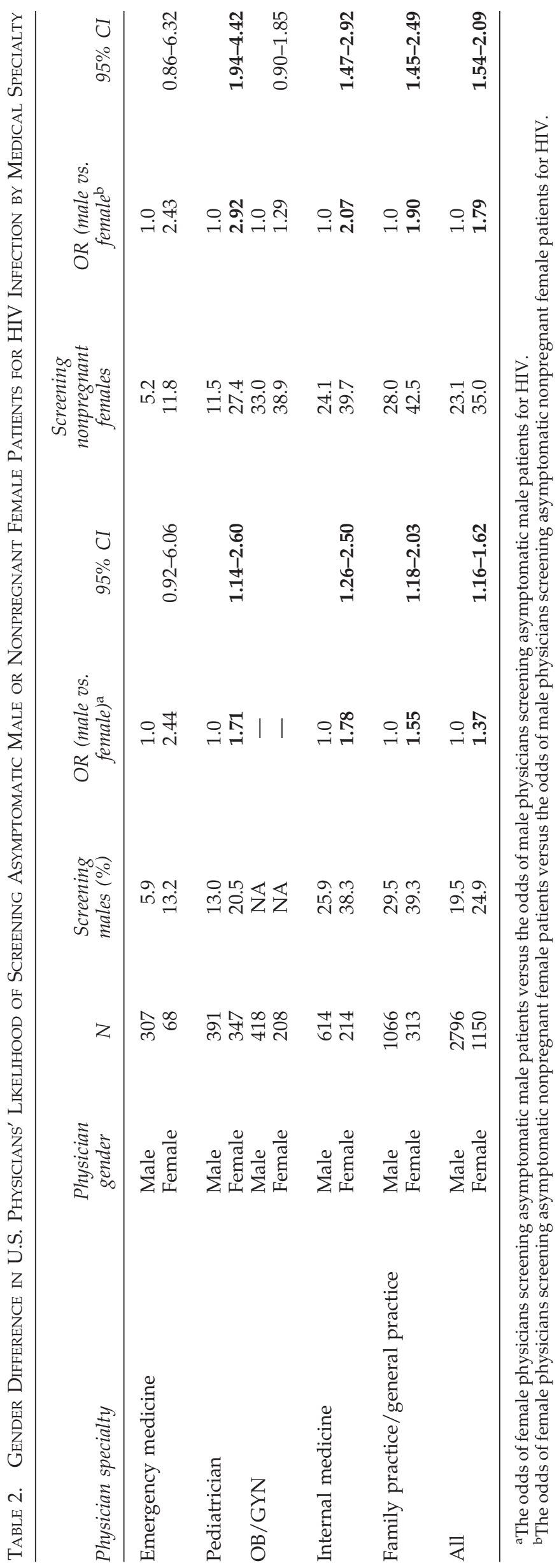


goals in both documents, however, remained directed to high prevalence settings or high-risk individuals and would not therefore be expected to produce changes in HIV screening practices in most of the geographic areas or practice settings covered by this survey. However, in New York City, which has the most AIDS cases in the United States, a survey conducted in 2005 found similar HIV screening rates among providers in the same specialties as the 2000 national survey reported here (M. Rogers, personal communication, November 15, 2006).

Physician attitudes were associated with offering HIV testing in univariate analyses. More positive views on HIV case reporting and partner services were associated with a higher likelihood of HIV screening. For example, doctors who usually or always reported sexual partner names to the health department were $30 \%$ more likely to offer HIV testing and those who only encouraged patients with AIDS to contact their partners themselves were less likely to test. Yet, it is possible that physicians who infrequently or never identified a patient as HIV positive would be less likely to know that reporting sexual partner names is required.

Furthermore, attitudes were generally correlated with each other and could therefore drop out of multivariate models on that basis alone. Finally, attitudinal variables may also mediate the relationships between structural conditions and the physician decision to offer testing. Future research efforts may test whether the attitudes reported in this survey change as a function of the new guidelines.

Practice characteristics and demographics accounted for more differences than did attitudes in those who offered testing and those who did not. Physicians were most likely to offer HIV screening if they were female, non-white, in a specialty other than emergency medicine, practiced in a large city or any region other than the South. Additionally, the physicians who were most likely to offer HIV screening were also more likely to have diagnosed an HIV patient in past 2 years. Surprisingly, internal medicine providers reported being less likely to offer HIV screening than family/general practitioners. This could be a result of the increased specialization among internists, the greater focus on ambulatory and preventive care among family and general practitioners or a combination of the two. ${ }^{24-26}$

Female physicians were more likely to screen for HIV than males, even after adjustment for other potential factors. Stratified analyses showed the difference is more pronounced for non-pregnant female patients and specialties other than emergency medicine and OB/GYN. Female physicians in primary care specialties often provide more routine gynecologic care (e.g., visits for routine pelvic examination with Papanicolaou smear). ${ }^{27}$ Such routine woman's health visits would be more likely to include preventive health care such as STD and HIV screening. Furthermore, discussion of, and testing for, HIV may be more likely for women who intend to become pregnant. Thus our findings may be partially explained by female physicians being more likely to provide such routine woman health visits with the type of visit, rather than gender, driving the increased likelihood of screening. However, we could not test this hypothesis directly. Also, female physicians were more likely than male physicians to screen male patients. Thus, further research is necessary to fully understand the gender differences among providers.
Analogously, non-white physicians in this survey had higher non-white patient loads than did white physicians. Therefore, their higher screening rates may be consonant with accurate perceptions of HIV morbidity among their patients. However, we examined the average number of HIV diagnoses providers reported during their careers (adjusted for years of practice) and found no difference across racial/ethnic categories. Disparities in HIV rates are most extreme for black and Hispanic individuals, and the screening rates of black and Hispanic physicians were both higher than for whites. When we explored the association between race/ethnicity and screening by public or private practice setting and whether the physician practiced in a large city, no effect modification was found. Also, the strong associations between race/ethnicity and HIV screening remained even after adjustment for these and other possible confounders. It is possible that providers are acting as "lay epidemiologists," making assessments as to the prevalence of $\mathrm{HIV}$ in their practice settings, and offering screening based on these assessments.

Regional precedent and institutional philosophy may play a particularly important role in the promotion of HIV screening, as well as all public health interventions. At a more proximate level to patient care, practice setting and location were correlated with odds of physicians offering HIV testing. For example, physicians practicing in smaller urban areas or in private clinics may perceive their patients at a reduced risk for HIV infection and therefore screen less frequently. Large institutions with more formal health care structures and that are typically more attuned to preventive health care and health care costs (i.e., managed care organizations) were more likely to feature physicians offering testing to patients, whereas private clinics and physicians with more privately insured patients were not.

Emergency departments (EDs) were the clearest example of a link between institutional structure and the likelihood of offering testing. Although it has been recommended ${ }^{21}$ and endorsed, ${ }^{28}$ HIV testing is largely not done in U.S. EDs. ${ }^{28-33}$ With HIV seroprevalence in estimated to be between $2 \%-17 \%,{ }^{29}$ EDs are clinical sites where routine HIV testing might be most cost-effective. However, adding further tasks to EDs' current portfolio requires caution. A previous study from these data suggested a role for EDs in STD sex partner management, but also noted the need for public health to take up case management after disease detection through links with EDs. ${ }^{31}$

This analysis has several limitations. This survey was not designed to explicitly assess HIV screening practices, but a constellation of reproductive health issues. As a cross-sectional survey, we cannot impute causal relationships among the variables we collected. Additionally, although the response rate was high, it is possible that nonrespondents were more or less likely to screen their patients for HIV, which could result in biased results. We report the most recent information available regarding the HIV screening practices of physicians in the United States. While the results are a number of years old, these data provide a glimpse into the possible mechanism and barriers to HIV screening in the United States.

Furthermore, given the more widespread use of oral and blood-based rapid HIV testing ${ }^{34}$ the proportion of U.S. physicians offering HIV screening may have increased since these 
data were collected. Also, we did not specifically question providers about routine HIV screening among their patients. Furthermore, we do not know if those classified as "HIV screeners" routinely offered all their patients HIV testing or only tested a subset of patients, which is more likely. Thus, our results likely overestimate the actual amount of HIV screening offered at the time.

Here we report low rates of HIV screening offered by providers in the United States. As states and localities attempt to incorporate the most recent CDC guidelines which call for universal HIV screening, ${ }^{2}$ a more complete understanding of the current practices will prove critical in creating environments in which routine HIV testing can become a reality.

\section{References}

1. Centers for Disease Control and Prevention. HIV / AIDS Surveillance 2004. Altlanta, GA: 2005.

2. Branson BM, Handsfield HH, Lampe MA, et al. Revised recommendations for HIV testing of adults, adolescents, and pregnant women in health-care settings. MMWR Recomm Rep 2006;55:1-17; quiz CE11-14.

3. Frieden TR, Das-Douglas M, Kellerman SE, Henning KJ. Applying public health principles to the HIV epidemic. N Engl J Med 2005;353:2397-2402.

4. Paltiel AD, Weinstein MC, Kimmel AD, et al. Expanded screening for HIV in the United States-An analysis of costeffectiveness. N Engl J Med 2005;352:586-595.

5. Sanders GD, Bayoumi AM, Sundaram V, et al. Cost-effectiveness of screening for HIV in the era of highly active antiretroviral therapy. N Engl J Med 2005;352:570-585.

6. Holtgrave DR. Costs and consequences of the US Centers for Disease Control and Prevention's recommendations for opt-out HIV testing. PLoS Med 2007;4:e194.

7. Achievements in public health. Reduction in perinatal transmission of HIV infection-United States, 1985-2005. MMWR Morb Mortal Wkly Rep 2006;55:592-597.

8. Castilla J, Sobrino P, De La Fuente L, Noguer I, Guerra L, Parras F. Late diagnosis of HIV infection in the era of highly active antiretroviral therapy: Consequences for AIDS incidence. AIDS 2002;16:1945-1951.

9. Wortley PM, Chu SY, Diaz T, et al. HIV testing patterns: Where, why, and when were persons with AIDS tested for HIV? AIDS 1995;9:487-492.

10. Dybul M, Bolan R, Condoluci D, et al. Evaluation of initial CD4 $+\mathrm{T}$ cell counts in individuals with newly diagnosed human immunodeficiency virus infection, by sex and race, in urban settings. I Infect Dis 2002;185:18181821.

11. Marks G, Crepaz N, Senterfitt JW, Janssen RS. Meta-analysis of high-risk sexual behavior in persons aware and unaware they are infected with HIV in the United States: Implications for HIV prevention programs. I Acquir Immune Defic Syndr 2005;39:446-453.

12. Roome A, Carley K, Melchreit R, Foye G, Hadler J. Testing pregnant women for HIV: A survey of obstetricians and review of patient prenatal/obstetric medical records-Connecticut 1996-1997. Conn Med 1999;63:523-529.

13. Nichols SA, Bhatta MP, Lewis J, Vermund SH. Prenatal HIV counseling, testing, and antiretroviral prophylaxis by obstetric and family medicine providers in Alabama. Am J Med Sci 2002;324:305-309.

14. Barnes RS, Anderson LA, Weisbord JS, Koumans E, Toomey
KE. Georgia prenatal care providers' perceptions of barriers to sexually transmitted disease screening. South Med J 2003;96:845-849.

15. Weisbord JS, Koumans EH, Toomey KE, Grayson C, Markowitz LE. Sexually transmitted diseases during pregnancy: Screening, diagnostic, and treatment practices among prenatal care providers in Georgia. South Med J 2001;94: 47-53.

16. Olges JR, Murphy BS, Caldwell GG, Thornton AC. Testing practices and knowledge of HIV among prenatal care providers in a low seroprevalence state. AIDS Patient Care STDs 2007;21:187-194.

17. Simmons E, Roberts M, Ma M, Beckwith C, Carpenter C, Flanigan T. Routine testing for HIV in the United States: The intersection between recommendations and practice. AIDS Patient Care STDs 2006;20:79-83.

18. St Lawrence JS, Montano DE, Kasprzyk D, Phillips WR, Armstrong K, Leichliter JS. STD screening, testing, case reporting, and clinical and partner notification practices: A national survey of US physicians. Am J Public Health 2002; 92:1784-1788.

19. Hing E, Burt CW. Characteristics of office-based physicians and their practices: United States, 2003-04. Vital Health Stat 13 Jan 2007(164):1-34.

20. Bozzette SA. Routine screening for HIV infection-Timely and cost-effective. N Engl J Med 2005;352:620-621.

21. Recommendations for HIV testing services for inpatients and outpatients in acute-care hospital settings. MMWR Morb Mortal Wkly Rep 1993;42:157-158.

22. Revised guidelines for HIV counseling, testing, and referral. MMWR Recomm Rep 2001;50:1-57; quiz CE51-19a51-CE56$19 \mathrm{a} 51$.

23. Advancing HIV prevention: New strategies for a changing epidemic-United States, 2003. MMWR Morb Mortal Wkly Rep 2003;52:329-332.

24. Backer EL, Gregory P, Jaen CR, Crabtree BF. A closer look at adult female health care maintenance visits. Fam Med May 2006;38:355-360.

25. Moore LG. Escaping the tyranny of the urgent by delivering planned care. Fam Pract Manage 2006;13:37-40.

26. Bertakis KD, Callahan EJ, Helms LJ, Azari R, Robbins JA, Miller J. Physician practice styles and patient outcomes: Differences between family practice and general internal medicine. Med Care 1998;36:879-891.

27. Cassard SD, Weisman CS, Plichta SB, Johnson TL. Physician gender and women's preventive services. J Womens Health 1997;6:199-207.

28. Rothman RE. Current Centers for Disease Control and Prevention guidelines for HIV counseling, testing, and referral: Critical role of and a call to action for emergency physicians. Ann Emerg Med 2004;44:31-42.

29. Rothman RE, Ketlogetswe KS, Dolan T, Wyer PC, Kelen GD. Preventive care in the emergency department: Should emergency departments conduct routine HIV screening? A systematic review. Acad Emerg Med 2003;10:278-285.

30. Wilson SR, Mitchell C, Bradbury DR, Chavez J. Testing for HIV: Current practices in the academic ED. Am J Emerg Med 1999;17:354-356.

31. Gift TL, Hogben M. Emergency department sexually transmitted disease and human immunodeficiency virus screening: Findings from a national survey. Acad Emerg Med 2006;13:993-996.

32. Fincher-Mergi M, Cartone KJ, Mischler J, Pasieka P, Lerner EB, Billittier AJt. Assessment of emergency department health care professionals' behaviors regarding HIV testing 
and referral for patients with STDs. AIDS Patient Care STDs 2002;16:549-553.

33. Liddicoat RV, Horton NJ, Urban R, Maier E, Christiansen D, Samet JH. Assessing missed opportunities for HIV testing in medical settings. J Gen Intern Med 2004;19:349-356.

34. Roberts KJ, Grusky O, Swanson AN. Outcomes of blood and oral fluid rapid HIV testing: A literature review, 2000-2006. AIDS Patient Care STDs 2007;21:621-637.
Address reprint requests to: Kyle Bernstein, Ph.D., Sc.M. STD Prevention and Control Services San Francisco Department of Public Health 1360 Mission Street, Suite 401 San Francisco, CA 94114

E-mail: kyle.bernstein@sfdph.org 